\title{
Reexamining the Market Timing Ability of Equity Funds in China-Cash-Flow and Discount-Rate Perspective
}

\author{
Zhaoying Zhang \\ Jinan University, Guangzhou, China \\ Email: fin2013050070@126.com
}

How to cite this paper: Zhang, Z.Y. (2019) Reexamining the Market Timing Ability of Equity Funds in China-Cash-Flow and Discount-Rate Perspective. Journal of Service Science and Management, 12, 767-789. https://doi.org/10.4236/jssm.2019.127052

Received: October 11, 2019

Accepted: November 13, 2019

Published: November 20, 2019

Copyright $\odot 2019$ by author(s) and Scientific Research Publishing Inc. This work is licensed under the Creative Commons Attribution International License (CC BY 4.0).

http://creativecommons.org/licenses/by/4.0/

\section{c) (i) Open Access}

\begin{abstract}
With the development of China's stock market, equity mutual funds are playing a more and more important role in shaping the market. However, with some many funds in the present market, which ones are able to predict the future market movements and adjust the risk exposure of their fund portfolios correspondingly to make reasonable return faced by various market conditions? Based on the former study, this paper uses a new method to reexamine the market-timing ability of open-end, equity funds in China, that is, to decompose the market-timing ability into cash-flow timing and discount rate timing. This differentiation provides a more specific metric to measure the funds' market timing performance besides rate of return, T-M measure and $\mathrm{H}-\mathrm{M}$ measure, etc. The empirical study reveals that on average, Chinese equity fund managers can bring about $0.58 \%$ excess return per year when timing the aggregate stock market, but it is not significant at any reasonable levels. However, the writer finds there have significant timing skill in Chinese equity fund managers who can predict the changes of discount rate and it is highly unlikely to find an equity fund that can make continuous positive return as it declares. Therefore, it is hard for a common investor to make abnormal returns through investing capital in the mutual funds for a long time.
\end{abstract}

\section{Keywords}

Equity Funds, Market-Timing Ability, Cash-Flow Timing, Discount Rate

\section{Introduction}

\subsection{Research Background}

Nowadays, investing in mutual funds has become more and more popular with 
individual investors. The mutual funds in China have experienced a golden stage since 2004, when the new Security Investment Funds Act was enforced. Until the end of 2015, there were 3358 open-end funds in China managing a pool of total net assets of 8.3 trillion RMB. However, only 87 close-end funds participated in security markets with total net assets of 0.1 trillion RMB. ${ }^{1}$ Therefore, individual investors are attaching more and more importance to the performance of open-end fund managers, and hope to invest in those superior funds to increase their wealth and spread the investment risks.

However, it is not an easy task for individual investors to tell those "excellent" fund managers from a huge number of funds with different qualities. Usually, fund managers are evaluated from 2 perspectives: the security-selection ability and market-timing ability. Since the security-selection skill is easier to observe in the financial market and is evaluated based on a common metric, empiricists focus more on measuring the market-timing ability of fund managers. It is well known that equity funds are exposed to relatively higher risks than other kinds of open-end funds (e.g. bond funds, monetary funds), because stock portfolios usually experience more fluctuations than any other securities. Their performances are more dependent on their managers' ability to adjust their portfolio when some significant changes have occurred in the stock market. Hence, this paper will focus on the market timing skill of Chinese domestic equity fund managers.

Through breaking the market timing ability into two parts: the cash-flow and discount-rate news using the methods in previous literature, the writer tries to develop a novel approach to evaluate the market timing performance of equity fund managers. This metric might help the fund managers to determine the components of their portfolio and the manner of allocating capital among different stocks or security classes when faced by various market situations (bullish or bearish). In addition, market-timing theory is extended from the CAPM and the examination of this metric provides another perspective to test the efficiency of Chinese stock market and the fairness of stock prices. What's more, market-timing skill is closely related to the real macro-economy and can be used by government as an indicator of the health of the whole economy.

\subsection{Literature Review}

\subsubsection{Decomposing the Performance of Fund Managers}

The study on market-timing ability began in 1966 after the classical CAPM was founded. During the past 50 years, researchers have developed the well-known T-M model, H-M model, CL-four-factor model etc. to measure the market-timing ability of fund managers. Treynor and Mazuy (1966) [1] add a quadratic term in the classical CAPM to capture the market-timing ability of fund managers. This T-M model is based on the simple idea that if fund managers can really time the market, then their characteristic line between fund return and ${ }^{1}$ China Galaxy Securities: The Size of Chinese Open-end Mutual Funds exceeds 8.4 trillion RMB in 2015, Fenghuang Finance, 2016, http://finance.ifeng.com/a/20160105/14150509_0.shtml. 
market return should be concave upward. Then Fama (1972) [2] first put forward a framework to evaluate the forecasting skills of investors: the microforecasting, which is related to anticipating the price movements of stocks; the macroforecasting, which is concerned with predicting the general price movements of the stock market. This paper marks the formation of the classical evaluation mechanism for the performance of equity mutual funds: the stock-selection and market-timing skills. After that, in order to make their conclusions more generalized without holding the CAPM framework, Henriksson and Merton (1981) [3] advocate a new model in which a dummy variable is included to test the two forecasting skills. They believe that fund managers time the market by anticipating whether stocks will make a higher return than bonds instead of how large this difference will be.

\subsubsection{Extensions of Market-Timing Models}

However, both the T-M and H-M model only take the market/systematic risk into consideration when evaluating the market-timing skill. Some factors that might explain the performance of mutual funds are excluded from these 2 models and there exists a specification bias. Hence, Fama and French (1993) [4] establish a multifactor model, which includes term structure of bond rates, size, $\mathrm{BE} / \mathrm{ME}$ and the stock market return, to measure the market-timing skills of mutual funds. The classical market-timing models, no matter the T-M, H-M or the Fama-French-multifactor model, all treat the market excess return/market risk premium as inseparable when running the time-series regression and reveal zero or even negative timing ability. In order to fix this problem, Chunhua and Wermers (2017) [5] decompose the market excess return into 2 sources: aggregate cash-flow news and discount rate news. They believe that fund managers anticipate the market movements based on the information about future cash-flow and discount rates. This is the first time for researches to separate the market risk premium into different factors.

\subsubsection{Empirical Tests of Market-Timing Ability across the World}

In addition to constructing the research framework for market-timing skill, researchers from all over the world have conducted studies across different financial markets to test the market-timing skill. For example, Ferson and Schadt (1996) [6] modify the approaches of Treynor-Mazuy and Henriksson-Merton and use monthly data for 67 mutual funds in US over the 1968-1990 period for empirical analysis. As a result, they find that the evidence of negative market-timing ability for funds in the sample is not convincing. Then Danie, Grinblatt, Titman and Wermers (1997) [7] employ the Carhart four-factor model to test 2500 asset data from 1975 to 1994 in order to find out whether the strategy used by the US fund managers might be superior to simple investment strategy. They find that on average, fund managers' strategies do not result in a much larger return than simple investment strategies do and that no market-timing skills exist even in those funds targeting at growth type stock. 


\subsection{Research Framework}

Following the steps taken by Chunhua and Wermers (2017) [5], this thesis focuses on the market-timing performance of 18 actively managed equity funds in China from 2012 to 2016 by decomposing the stock market return into cash-flow news and discount-rate news. Instead of estimating the fund's beta directly, the writer employs a bottom-up method to derive the fund's systematic risk exposure more accurately. Then a bootstrap procedure is used to test the significance of market-timing skills. The author also pays attention to the persistence of those funds' market-timing skills based on the timing performance in the past $0.5,1,1.5$ year.

\section{Current Market-Timing Performance of Equity Funds in China}

Before decomposing the stock market return into cash-flow and discount-rate component, the market-timing ability of Chinese domestic equity funds will be examined first using some traditional indicators. The previous literature all points out that if the manager of an equity fund really has some specific skills in anticipating the future market movements, then he/she should be able to shift the portfolio's risk sensitivity by reallocating capital into different assets according to different market conditions as time goes by. This reallocation procedure could be achieved by switching the investment asset classes. Hence, in the rest of this section, the writer will compare the performance of equity funds with those of risk-free asset, aggregate bond market, aggregate stock market, hybrid funds and bond funds based on different return measurements, such as quarterly return, Sharpe ratio and Jensen ratio from Jan, 2011 to Mar, 2017. Through comparison, readers might be able to identify the market-timing skills in equity fund managers.

\subsection{Market-Timing among Asset Categories in the Capital Market}

In this part, the writer investigates the market-timing performance among risk-free asset, bond market portfolio, stock market portfolio and the equity funds using classical return measurements. It is well-known that the capital market usually consists of a risk-free asset and a portfolio of risky assets. If the equity fund managers are believed to have market-timing skills, then their portfolio's beta (systematic risk sensitivity) should be larger when the market is rising and vice versa. Put it differently, if the performance of equity funds is superior to those of risk-free asset and bond market portfolio in the long run, then this might be achieved when managers are able to predict the future market movements and shift the securities accordingly. In the comparison procedure, the 3-month SHIBOR is used as a proxy of the quarterly return of risk-free asset, the China Bond New Wealth Index as a representation of bond market portfolio, the Wind A-class Level as a proxy of equity market portfolio, and the change of accumulated unit net asset value as the return of equity funds. 


\subsubsection{Quarterly Return Comparison}

The quarterly return of a portfolio during the sample period is the simplest and most direct way to measure its performance. The writer downloads the relevant data from Wind and derives the following results.

From Table 1 and Figure 1, there are some interesting facts worth noticing among the first group. During the past five years, on average, the equity funds only make a return of $2.0 \%$, which is less than those of the risk-free asset $(4.16 \%)$ and bond market index (3.9\%). In most of the time, equity funds were unable to beat the market and their counterparts. This phenomenon is obvious in those times when the policy and economic uncertainty rose to a significant level. For example, from 2011 to 2012, China's economy gradually slowed down after its high growth due to the declining utility of the expanding fiscal policies in 2008. During this interval, some underlying problems such as low-quality growth model, excess productivity, high leverage in manufacturing enterprises etc., were emerging and increasing the systematic risk. Hence, equity funds invested in those listed companies inevitably experienced a decline in return in this year. Another interesting finding is that the return of equity funds could decline sharply to negative levels when the market experienced noticeable fluctuations. In 2015, a new mechanism was introduced to the stock market and triggered a mass drop in market capitalization. Correspondingly, the equity funds' return jumped from over $10 \%$ to a negative value. Many managers were fired because of the poor performance in the management. In addition, the standard deviation of equity funds' return is much larger, together with a larger maximum and a

Table 1. Descriptive statistics of quarterly return of asset categories in the capital market.

\begin{tabular}{ccccccc}
\hline & Mean & Minimum & Maximum & S.D. & Skewness & Kurtosis \\
\hline Equity Funds & 0.02006 & -0.2721 & 0.4051 & 0.1362 & 0.5972 & 4.3453 \\
Equity Market Index & 0.0299 & -0.3292 & 0.3101 & 0.0298 & 0.0070 & 0.4323 \\
Risk-free Asset & 0.0416 & 0.0279 & 0.0561 & 0.0019 & -0.0905 & -1.2467 \\
Bond Market Index & 0.0390 & 0.0297 & 0.0518 & 0.0011 & 0.3716 & 0.4094 \\
\hline
\end{tabular}

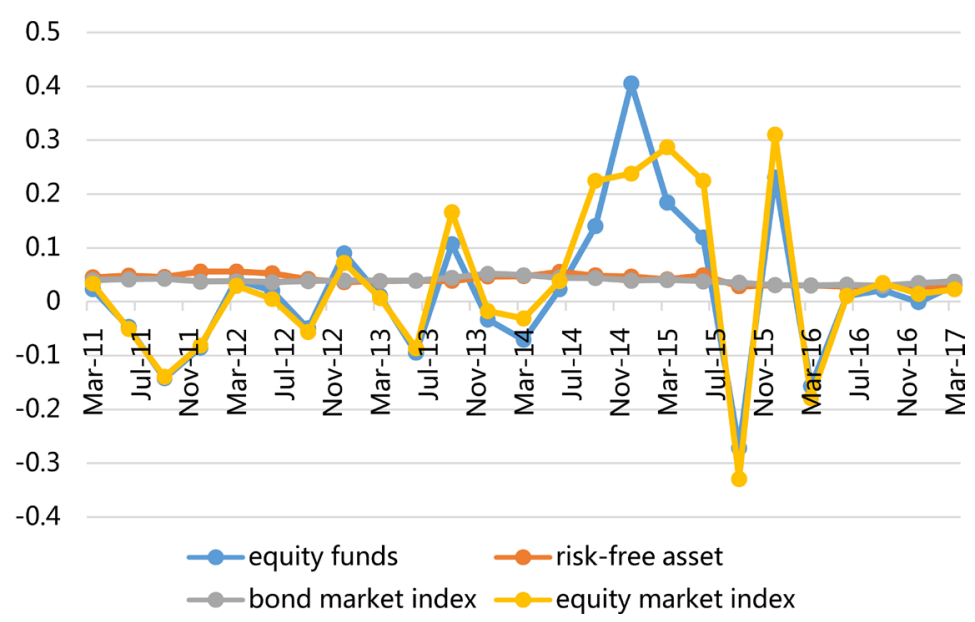

Figure 1. The Quarterly Return of asset categories in the capital market. 
smaller minimum. This situation implies that the return of equity funds fluctuates more severely and the persistence of making a return better than benchmarks is not significant. And from Figure 1, in most of the time, the return line of equity funds runs beneath those of the risk-free asset and bond market index. Although the equity funds add a positive value to the portfolio at some specific time when the market is rising (e.g. from March, 2014 to March, 2015), the return begins to drop sharply to a negative value as soon as the market is declining. What's more, the trend of the equity funds is nearly the same to that of the aggregate stock market. It is intuitive that market-timing ability is not significant among the equity fund managers based on the observations mentioned above. And equity funds make a higher return during a bullish market mainly because the stocks in their portfolio have larger risk sensitivity than risk-free asset and aggregate bond market instead of the market-timing ability. If the equity fund managers are really talented in timing the market, then their return will be much smoother and the return won't drop at the same magnitude as the stock market when the whole market is declining.

\subsubsection{The Monthly Sharpe Ratio Comparison}

The Monthly Sharpe Ratio of a portfolio for the past three years is defined as the following equation:

$$
S_{p}=\frac{\overline{R_{p}}-\overline{R_{f}}}{\delta_{p}}
$$

where $\overline{R_{p}}$ and $\overline{R_{f}}$ are the average monthly return of the portfolio and the average monthly risk-free rate during the sample period, respectively, while $\delta_{p}$ is the standard deviation of the monthly return in the corresponding time. It is intuitive that the Sharpe Index measures the return a portfolio can make for one unit of total risk incurred.

According to the Sharpe Ratio calculated by Equation (1), Table 2 shows that the bond market index is an outlier to its counterparts in every basic indicator, which is due to larger average monthly returns and smaller standard deviation during the sample period. Hence, in order to avoid spurious results, we draw the line of bond market index on a subordinate and get Figure 2 to examine the performances of asset categories in the capital market. It is clear that the trend of the equity funds is quite similar to that of risk-free asset but is relatively different from that of equity market index. This situation suggests that equity funds are

Table 2. Descriptive statistics of Sharpe ratio of asset categories in the capital market.

\begin{tabular}{ccccccc}
\hline & Mean & Minimum & Maximum & S.D. & Skewness & Kurtosis \\
\hline Equity Funds & 0.0001 & -0.0154 & 0.0174 & 0.0105 & 0.2282 & 1.4967 \\
Equity Market Index & 0.0877 & -0.1357 & 0.3531 & 0.151 & 0.0036 & 1.6678 \\
Risk-free Asset & 0 & 0 & 0 & 0 & 0 & 0 \\
Bond Market Index & 8.7862 & 5.3598 & 16.3852 & 2.4766 & 1.2381 & 4.9160 \\
\hline
\end{tabular}




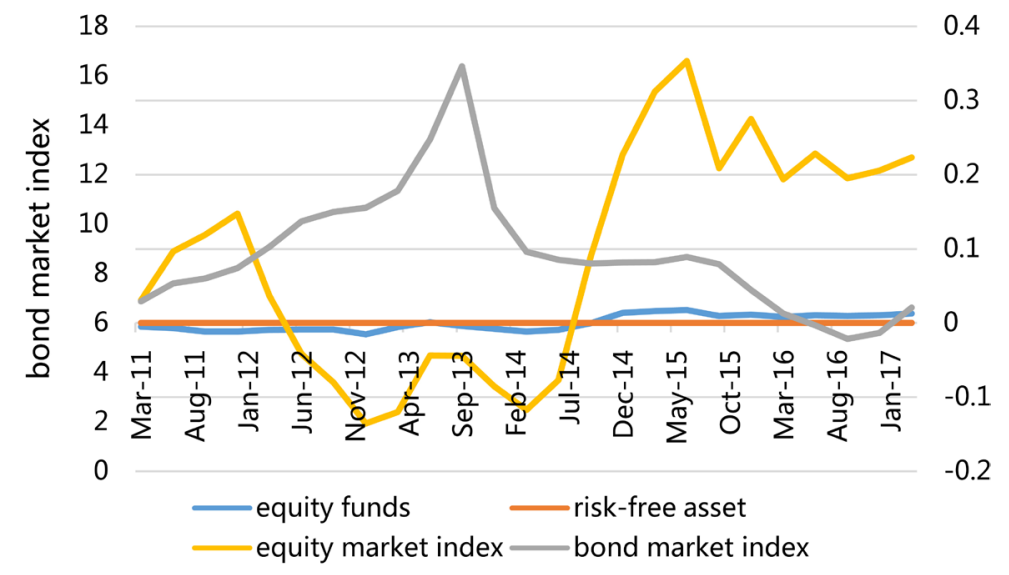

Figure 2. The Sharpe Ratio of asset categories in the capital market.

unable to make a significant positive return for the total systematic risks they bear, with an average Sharpe Ratio of only 0.0001 . This is mainly explained by the risk levels of those assets the fund managers invested in. It is well known that fund managers are prone to stable management and are unwilling to invest in those high-risk firms. Therefore, the return of equity funds is much lower compared to the overall stock market as fund managers usually focused more on blue-chip enterprises to meet their target return. Another abnormal phenomenon is that based on the Sharpe Ratio, the equity funds outperform the aggregate stock market at some periods when the market is declining (e.g. from Mar, 2012 to Dec, 2012), however, their performance is far more inferior to that of the equity market index when the market is rising. Hence, it seems that the equity fund managers cannot take a chance to make a higher return even when the market is good. Combined with the findings in 2.1.1, it is hard to say that equity fund managers are able to anticipate the future stock market movements, neither up nor down.

\subsection{Market-Timing among Asset Categories in Open-Ended Fund}

The risk-free asset, bond market index and equity market index represent portfolio on the macro level and might not be so accurate to reflect the real market-timing performance of equity funds through comparison. Hence, in order to take a deeper look at whether the managers of equity funds can time the market for some time, we introduce another group of counterparts for comparison: the hybrid and bond funds in China, which depends more on the micro level. If equity funds reveal a significant better return than the other two kinds of funds during the sample period, then perhaps equity funds can achieve this by continuously timing the market.

\subsubsection{The Quarterly Return Comparison}

The quarterly return of a certain kind of fund is derived by calculating the weighted average of quarterly return, using the fund's total net asset value as the weight.

Figure 3 and Table 3 shows that the average returns for the three kinds 


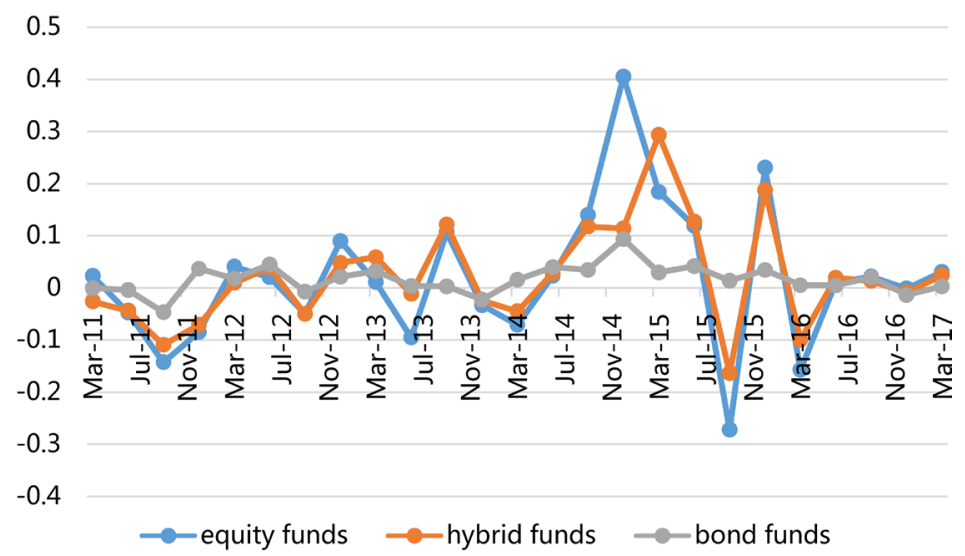

Figure 3. The quarterly return of hybrid funds, bond funds and equity funds.

Table 3. Descriptive statistics of quarterly return of hybrid funds, bond funds and equity funds.

\begin{tabular}{ccccccc}
\hline & Mean & Minimum & Maximum & S.D. & Skewness & Kurtosis \\
\hline Equity Funds & 0.02006 & -0.2721 & 0.4051 & 0.1362 & 0.5972 & 4.3453 \\
Hybrid Funds & 0.0221 & -0.1635 & 0.2936 & 0.0199 & 0.7314 & 1.1747 \\
Bond Funds & 0.0160 & -0.0465 & 0.0937 & 0.0055 & 0.4194 & 2.0892 \\
\hline
\end{tabular}

of mutual funds in China are quite similar, $2 \%, 2.21 \%, 1.6 \%$ for the equity funds, hybrid funds and bond funds, respectively. However, when we look at the standard deviation and the band values, we also find that equity funds have a more unstable performance during both the rising and declining market. From 2011 to 2013, China's economy slowed down its high growth pace and all kinds of risks were emerging. During this interval, the return of equity funds experienced both surge and decline, which drew up the standard deviation of return. However, after 2014, the central government decided to implement the structural reform to build a high-quality growth model. Fiscal and monetary policies were introduced to stimulate the relevant industries. Hence, the average return of equity funds gradually rose to a positive value. However, in the second quarter of 2015, a new mechanism was introduced to the stock market and the average return of equity funds experienced a sharp drop to a negative value. In a word, due to the high fluctuation in the stock market, the performance of equity funds could vary significantly during both the expanding and declining economies. This is due to the components of the portfolio in different kinds of funds. It is well known that fixed-income securities bear a smaller risk than equities, and higher proportion of bonds in the hybrid and bond funds can help cushion the price shocks mainly from the stock market. It seems that it is the financial instrument itself that help smooth the portfolio return. Hence, the market-timing ability cannot be found even in the hybrid and bond funds.

\subsubsection{The Monthly Sharpe Ratio Comparison}

The monthly Sharpe Ratio in the past three years of a certain kind of fund is de- 
rived by calculating the weighted average of the metric, using the fund's total net asset value as the weight.

According to the monthly Sharpe Ratio displayed in Figure 4 and Table 4, in general the equity funds underperform their counterparts in the past five years (the smallest mean among the three types of funds). However, if we examine the trend of these three funds, we find that in the latter half of the sample period (from Sept, 2014 to Mar, 2017), the equity funds continuously outperform the other two even when the market is declining (see Figure 1 and Figure 3 for reference). This situation implies that the equity funds do reveal some timing skills after Sept, 2014 and we will explore this question much further in the rest of this paper.

\section{Methodology of Decomposing Market-Timing Ability}

\subsection{Theoretical Backgrounds}

Beginning with Treynor and Mazuy and Henriksson and Merton, researchers usually examine the changes of CAPM beta of a mutual fund's portfolio to measure the market-timing ability of the fund manager: that is, increase the fund's beta when the stock market is rising or decrease it when the stock market is declining. The market return is treated as one piece when regressions are used and many findings suggest that there is little or even negative market-timing ability.

However, it might be inappropriate to run regressions on the fund's return directly against the total market return. It is well-known that professional investors

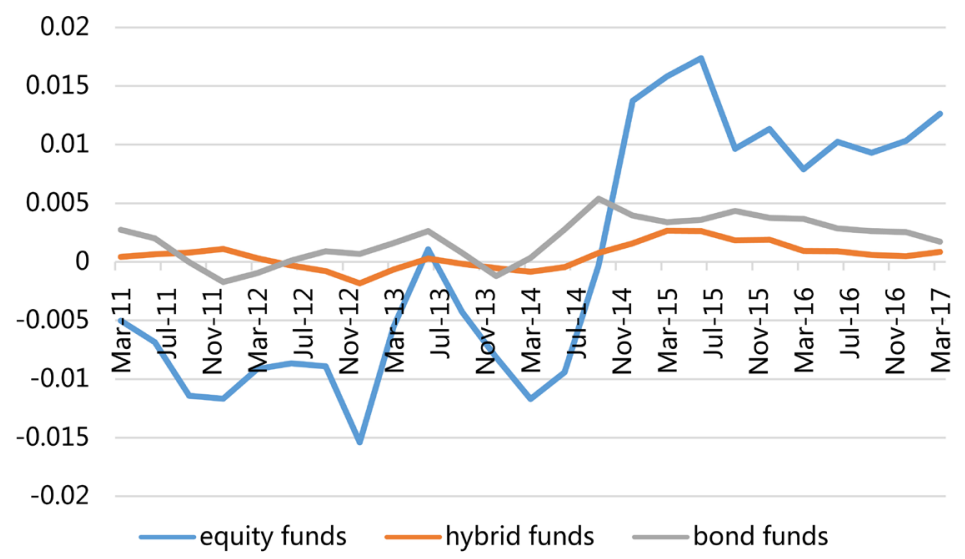

Figure 4. The monthly Sharpe ratio of hybrid funds, bond funds and equity funds.

Table 4. Descriptive statistics of monthly Sharpe ratio of hybrid funds, bond funds and equity funds.

\begin{tabular}{ccccccc}
\hline & Mean & Minimum & Maximum & S.D. & Skewness & Kurtosis \\
\hline Equity Funds & 0.0001 & -0.0154 & 0.0174 & 0.0105 & 0.2282 & 1.4967 \\
Hybrid Funds & 0.0005 & -0.0018 & 0.0026 & 0.0011 & 0.0906 & 2.7855 \\
Bond Funds & 0.0019 & -0.0017 & 0.0054 & 0.0018 & -0.2864 & 2.2770 \\
\hline
\end{tabular}


often analyze the future market movements from various aspects: macroeconomy situation, government policy, financial system, risk-free rates etc. because there are quite a few risks in the stock market. Hence, it is advisable to decompose the total market return when considering the market exposure of a fund's portfolio. According to asset pricing model, financial assets are mainly affected by 2 factors: the future cash flow and future discount rates, which are the main sources of uncertainty or risks faced by investors at the same time. Besides, some literature has examined the importance of dividing market return into cash-flow risk and discount rate risk when explaining the size and value anomalies in stock returns. Campbell and Vuolteenaho (2004) emphasize that it is necessary to differentiate the market return into these two factors since a rational investor considers them in a different way: a higher return is required for bearing the cash-flow risk than bearing the discount-rate risk according to the intertemporal asset pricing theory. So if the fund managers really have the ability to predict the future market movements and adjust the components or allocation of their portfolio, then cash flow and discount rate news should be exploited separately first.

Following the methods used by Chunhua and Wermers (2017) [5], we divide the total market return into cash-flow and discount-rate parts based on the Gordon-Growth model:

$$
P_{t}=\frac{e_{t}}{r_{t}-g_{t}}
$$

where $P_{t}$ and $e_{t}$ are stock market prices and corporate future earnings at time $t$, respectively, and $r_{t}$ and $g_{t}$ are the time-t expected return and expected earnings growth rate forever, respectively. This model is based on the assumption that the expected return is larger than the expected growth rate. Taking a first-order Taylor expansion of the above formula leads to

$$
\frac{\Delta P_{t}}{P_{t}}=\frac{-P_{t}}{e_{t}}\left(\Delta r_{t}-\Delta g_{t}\right)=\frac{P_{t}}{e_{t}} \Delta g_{t}-\frac{P_{t}}{e_{t}} \Delta r_{t}
$$

in which $\Delta g_{t}$ and $\Delta r_{t}$ are time-t changing expectations of future earnings growth and discount rates, respectively, and $\frac{P_{t}}{e_{t}}$ is the time-t static PE ratio. This equation implies that the total stock market return $\frac{P_{t}}{e_{t}}$ can be divided into 2 parts: a cash-flow component $\frac{P_{t}}{e_{t}} \Delta g_{t}$ and a discount-rate component $\frac{P_{t}}{e_{t}} \Delta r_{t}$. Then we evaluate the excess return on the cash-flow news and discount-rate news after subtracting the risk-free rate from $\frac{P_{t}}{e_{t}} \Delta g_{t}$ and $\frac{P_{t}}{e_{t}} \Delta r_{t}$.

\subsection{Procedure}

\subsubsection{Evaluate the Excess Return for Individual Stocks}

We download relevant data from Wind. Firstly, we choose Wind A-level Stock 
Index as a representative of the Chinese stock market. Then we derive the total earnings of all stocks in this index by $\frac{P}{P / E}$. After that, the monthly changes of aggregate earnings growth rate are calculated as an approximation of $\Delta g$. Along with the available monthly P/E data and return on the stock, we are able to estimate the return on a systematic factor (cash-flow news or discount-rate news) according to the formula in 3.1. Finally, we subtract the monthly risk-free rate from the systematic factor return to get the excess return on this factor.

\subsubsection{Estimate Factor Sensitivities for Individual Stocks}

As mentioned before, market-timing ability is related to how fund managers shift the beta of their portfolio to a systematic factor over time. Since a fund's beta respect to a systematic factor cannot be estimated by simply running a regression on fund's return against the return on the factor, we adopt a bottom-up way to evaluate the fund's beta. This method implies that, with detailed stock holdings data, the betas of an individual stock to systematic factors (cash-flow news, discount rate news or the total market return) are derived by regression and then fund's beta can be estimated as the value-weighted average of stock beta for all stocks belonging to this fund. In order to make comparison between treating the market return as one piece and decomposing it into two parts, we adopt two models to capture systematic risks: one is a two-factor linear model with cash-flow news and discount-rate news as regressors, the other one is the Fama-French three-factor model with total market return as one of the independent variables.

The two models center at the following equation:

$$
r_{i, t}=\alpha_{i, t}+\sum_{n=1}^{N} \beta_{i, n, t} K_{n, t}+u_{i, t}
$$

where $r_{i, t}$ is the stock $i$ excess return over the risk-free rate at time $t, \alpha_{i, t}$ is the abnormal return after adjusting for relevant risks, $K_{n, t}$ is the excess return on factor $n$ (cash-flow news, discount-rate news or the total market return) at time $t, \beta_{i, n, t}$ is stock is sensitivity to a systematic factor at time $t$ and $u_{i, t}$ is the residual form. If the two-factor model is used, then we can get the betas for cash-flow news and discount-rate news. If the Fama-French model is employed, then we can estimate the beta for total market return as a non-divisible risk. To avoid look-ahead bias and make the regression results more generalized, we run the above regression using the monthly data over the past 5 years (60 data in total) and eliminate those stocks without 24-month observations available (past 2 years).

\subsubsection{Calculate Factor Sensitivities for Funds}

After we obtain the betas to systematic factors of each individual stock in the fund, we calculate the fund's beta using the value-weighted average of stocks in the portfolio. Assume that $\beta_{f, n, t}$ is fund $f$ s sensitivity to a systematic factor $n$ at time $t, \omega_{i, f, t}$ is the stock is weight in fund $f$ at time $t$ derived by calculating the ratio of its market capitalization to that of the fund's stock portfolio, $P_{f, t}$ is 
the number of stocks with efficient observations more than 2 years in fund $f$ at time $t$. Hence, the fund $f$ s betas can be estimated by the following equation:

$$
\beta_{f, n, t}=\sum_{i=1}^{P_{f, t}} \omega_{i, f, t} * \beta_{i, n, t}
$$

It is important to know that the stock's weight in the portfolio can be changed in period $t$ because of fund manager's active market-timing (increase or reduce the capital allocated to a specific stock) or nonproportional price changes in different stocks. The latter situation is irrelevant to the market-timing skills of a fund manager, and since equity funds' holdings data are reported every 6 months, we suppose that individual stock's weight is stable during the 6-month period. That is, we can only calculate fund's betas at the end of June and December every year.

\subsubsection{Measure the Market-Timing Ability}

As Elton, Gruber and Blake (2012) [8] use a timing a measure that is parallel to the differential return measure used in measuring security selection ability, we imitate their idea and define the following differential timing measure:

$$
T M_{f, n, t}=\left(\beta_{f, n, t-1}-\overline{\beta_{f, n}}\right) K_{n, t}
$$

in which $T M_{f, n, t}$ represents the timing measure of fund $f$ in response to a systematic factor $n$ at time $t, \beta_{f, n, t-1}$ is fund $f$ s sensitivity to a factor $n$ at the beginning of period $t$, estimated according to Equation (3), and $\overline{\beta_{f, n}}$ is the time-series average of all betas to a systematic factor $n$ of fund $f, K_{n, t}$ is the excess return or differential return for factor $n$ in the month over which the beta is estimated. The $\beta_{f, n, t-1}-\overline{\beta_{f, n}}$ is termed as 'differential beta' in the rest of this paper. Then the timing measure to a systematic factor for a fund over all the sample periods will be:

$$
T M_{f, n}=\frac{1}{T} \sum_{t=1}^{T} T M_{f, n, t}
$$

where $T$ is the total number of periods with efficient observations. This measurement of timing is based on the idea that if fund managers can really time the market, then this can be achieved by varying the sensitivity of their funds from the average level.

\subsubsection{Calculate the t-Statistic of Timing Measure for Robustness}

According to Kosowski, etc. (2006) [9], a fund that exists for only a short period of time or bears high risks when constructing the portfolio usually has a larger variance of return. Hence, in order to eliminate the potential effects (e.g. spurious outlier in the cross section) brought by this situation and make our results more robust, we also evaluate the t-statistic of timing measure defined by the following equation:

$$
t=\frac{\widehat{T M}-T M}{\delta}
$$

where $\widehat{T M}$ is the actual timing measure, $T M$ is the expected timing measure 
under the null hypothesis, that is 0 in this paper, $\delta$ is the standard error of the sample return.

\subsubsection{Test the Significance of the Market-Timing Ability and the Corresponding T-Statistic}

The fifth step is to test the significance of our results by using the bootstrap method that is developed by Kosowski, etc. (2006) [9] and is employed by Jiang, Yao and Yu (2007) [10] and Elton, Gruber and Blake (2012) [8]. In the bootstrap procedure, for every 6 months, we first select the excess return on systematic factors (cash-flow news, discount-rate news and total marker return) $K_{n, t}$ randomly from each 6-month period from 2012 to 2016 (with 10 data in total). Then we multiply this randomly selected excess factor return during period $t$ by the actual differential beta $\beta_{f, n, t-1}-\overline{\beta_{f, n}}$ during period $t$ obtain the market-timing performance for each equity fund and the cross-sectional distribution of the performance. The time-series average of these multiplications produces a bootstrap timing measure for each fund. This procedure is repeated 100 times. Under the null hypothesis, the expected timing measures are zero. For points above (below) the median, p-value is the probability of a higher (lower) value occurring by chance. For a positive (negative) value of the mean or median of a timing measure, p-value is the probability of a higher (lower) value occurring by chance. The $\mathrm{p}$-value of the t-statistic is also derived in the similar manner.

\subsubsection{Test the Persistence of the Market-Timing Ability}

To test the persistence of fund managers' market-timing ability, every six months (since fund's holdings data is reported half a year) we sort the 18 funds into quintiles according to their market-timing performance in the past 1 year, 1.5 year and 2 years. Then we calculate the time-series average of the differential timing measure respect to a systematic factor, which is specified in Equation (6), across funds in each quintile.

\section{Empirical Analysis of Market-Timing Ability}

In this section, we provide the empirical results of estimating the market-timing performance based on the differential timing measure mentioned above. To make a comparison between decomposing the market return into two parts and treating it as one piece, we also report the results based on the regression on total market return. In addition, the persistence of funds' market-timing ability and the way to identify funds with market-timing ability are shown as well.

\subsection{Sample and Data}

This paper follows a method similar to that used by Lan and Wermers to select sample funds. Firstly, funds that invest in more than one kind of security are eliminated. Secondly, only those funds that have been in operation for more than five years are taken into consideration. Finally, passively managed equity funds (e.g. market-index funds) are also excluded from the sample. According to 
the sortation method in the Wind, 18 actively managed equity funds over the period from 2011 to 2016 are selected for further exploration.

The monthly holding data of actively managed equity mutual funds in China comes from the Wind database. The Wind provides detailed information about the stock name, stock market total net asset value, average daily/weekly/monthly return etc. In order to make the conclusion more convenient, stocks without more than 24 valid observations will be eliminated from the fund's portfolio when calculating the fund's beta and timing measure. The monthly risk-free rate, the return of individual stocks and the Fama-French three factors are downloaded from CSMAR from 2007 to 2016. While the relevant information about Wind A-class Level is downloaded from the Wind.

\subsection{Market-Timing Ability in Response to Cash-Flow Shocks}

Table 5 reports the results of timing cash-flow news of 18 actively managed equity funds in China during the sample period based on the differential timing measure in Equation (6). To find out the cross-sectional features among these funds, we sort them into the $5^{\text {th }}, 10^{\text {th }}, 25^{\text {th }}, 75^{\text {th }}, 90^{\text {th }}$ and $95^{\text {th }}$ percentiles according to their market-timing performances.

From Table 5, we find that on average, fund managers only make a return of $0.32 \%$ but funds in the middle class are able to make a significant positive return of $0.39 \%$ when timing the cash-flow news. In addition, the standard deviation reveals that the distribution of funds' cash-flow timing performance is quite dense. However, according to the $\mathrm{p}$-value and $\mathrm{t}$-statistic at each point, funds in the two tail of the distribution do not reveal a significant timing ability even at the $10 \%$ level of significance. In order to test the significance more accurately, we also draw the $95 \%$ confidence interval in Figure 5. This figure is based on the

Table 5. Empirical results of cash-flow timing.

\begin{tabular}{cccccc}
\hline \multicolumn{5}{c}{ Panel A: Descriptive Statistics } \\
\hline \multicolumn{1}{c}{ Mean } & Minimum & Maximum & S.D. & Skewness & Kurtosis \\
\hline 0.0032307 & -0.0035307 & 0.0098656 & 0.0042225 & -0.0420504 & 1.711319 \\
\hline \multicolumn{5}{c}{ Panel B: Tests of Significance } \\
\hline Quantiles & Tim & p-value (Tim) & t-statistic & p-value (t-statistic) \\
\hline $5 \%$ & -0.0035 & 0.77 & -0.84 & 0.77 \\
$10 \%$ & -0.0021 & 0.69 & -0.54 & 0.74 \\
$25 \%$ & -0.0011 & 0.63 & -0.36 & 0.64 \\
Mean & 0.0032 & 0.18 & 0.97 & 0.15 \\
Median & $0.0039^{*}$ & 0.09 & $1.33^{* *}$ & 0.01 \\
$75 \%$ & 0.007 & 0.12 & 1.78 & 0.13 \\
$90 \%$ & 0.0092 & 0.14 & 1.97 & 0.27 \\
$95 \%$ & 0.0099 & 0.21 & 1.74 & 0.45 \\
\hline
\end{tabular}

Note: Significance at the 1, 5 and 10 percent levels are indicated by ${ }^{* * *},{ }^{* *}$, and ${ }^{*}$ respectively. 


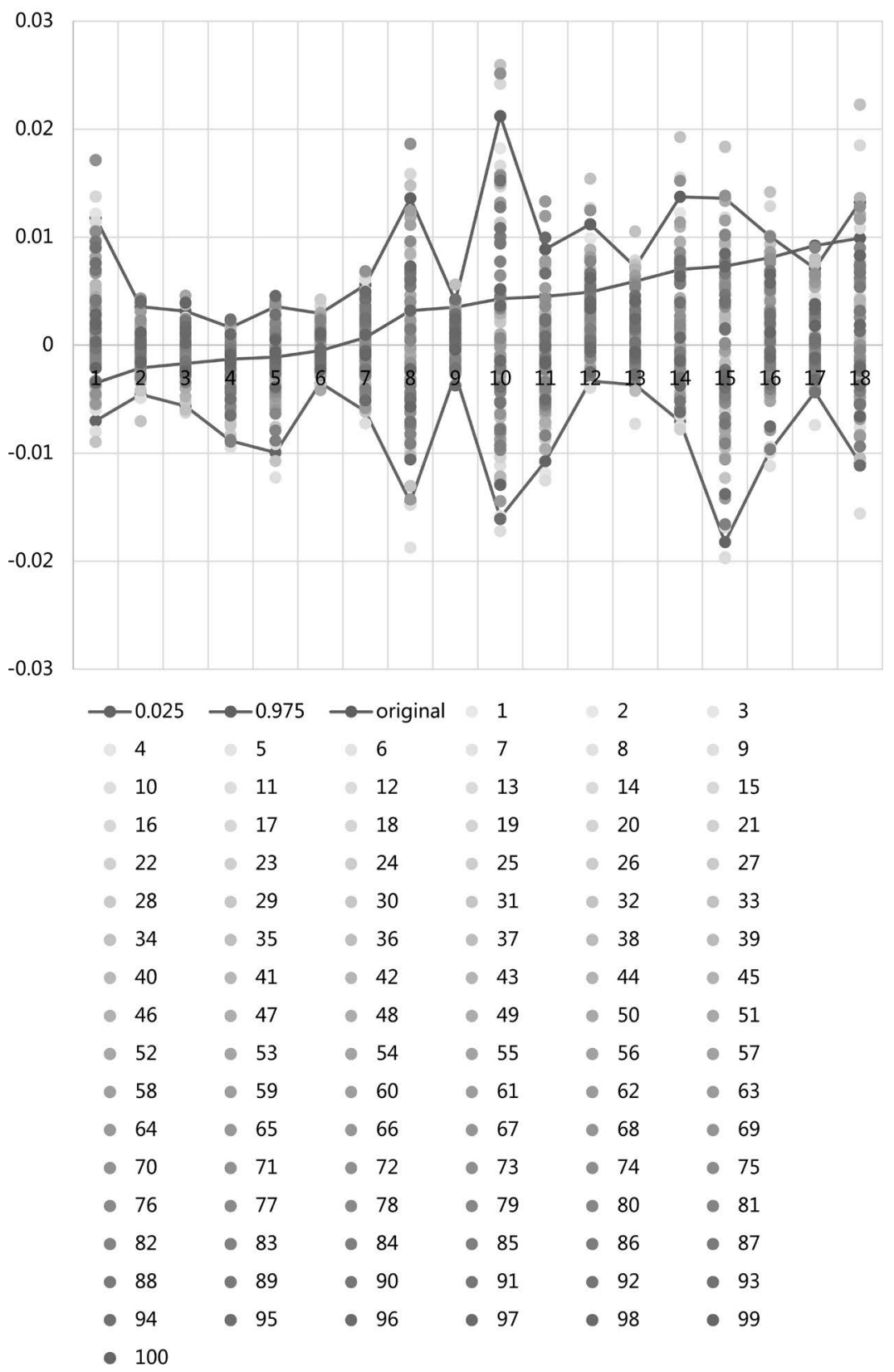

Figure 5. The $95 \%$ confidence interval of bootstrap procedure of cash-flow timing.

bootstrap procedure by picking a value from the corresponding percentile stochastically 100 times and calculate the average return in each time. Then the interval over the lowest $2.75 \%$ and lower than the highest $97.5 \%$ is marked and compared to the original performance. The graph reveals the similar findings as the p-value and t-statistic: all funds in the sample are not significant at the 5\% confidence level except the $17^{\text {th }}$ fund. Hence, market-timing ability response to cash-flow shocks is not significant in the sample funds at any reasonable levels.

\subsection{Discount-Rate Shocks}

Table 6 reports the results of timing discount-rate news of 18 actively managed 
equity funds in China during the sample period based on the differential timing measure in Equation (6). To find out the cross-sectional features among these funds, we sort them into the $5^{\text {th }}, 10^{\text {th }}, 25^{\text {th }}, 75^{\text {th }}, 90^{\text {th }}$ and $95^{\text {th }}$ percentiles according to their market-timing performance.

We can observe from Panel A that the sample funds make an average return of $-0.04 \%$ and most of funds make a negative return when timing discount-rate news according to the mean and the skewness. Besides, funds in different intervals do not reveal a significant timing ability except those in the $95 \%$ percentile. We also notice that the standard deviation and range of discount-rate timing measure are larger than those of cash-flow timing measure. Also, we depict the 95\% confidence interval in Figure 6 and only observe the 18th fund's original performance lies outside the confidence interval. Hence, the ability to time the discount-rate news might exist among those fund managers in the top interval but is not common among the equity funds.

\subsection{Aggregate Market Shocks}

Table 7 reports the results of timing both the cash-flow news and discount-rate news of 18 actively managed equity funds in China during the sample period based on the differential timing measure in Equation (6). To find out the cross-sectional features among these funds, we also sort them into the $5^{\text {th }}, 10^{\text {th }}$, $25^{\text {th }}, 75^{\text {th }}, 90^{\text {th }}$ and $95^{\text {th }}$ percentiles according to their market-timing performance.

When we add the cash-flow timing measure and discount-rate timing measure together, we find that on average, fund managers can add a positive value of $2.86 \%$ to their portfolio. And again, only funds in the $95 \%$ reveal a significant return of $5.64 \%$ according to the $\mathrm{p}$-value and $95 \%$ confidence interval, which is quite close to the significant return on discount-rate news of 5.33\%. From Figure 7, the

Table 6. Empirical results of discount-rate timing.

\begin{tabular}{cccccc}
\hline \multicolumn{5}{c}{ Panel A: Descriptive Statistics } \\
\hline Mean & Minimum & Maximum & S.D. & Skewness & Kurtosis \\
\hline-0.0003698 & -0.0122884 & 0.0532753 & 0.014473 & 2.966612 & 11.8553 \\
\hline Quantiles & Tim & p-value (Tim) & t-statistic & p-value (t-statistic) \\
\hline $5 \%$ & -0.0123 & 0.19 & -1.79 & 0.45 \\
$10 \%$ & -0.012 & 0.16 & -2.1 & 0.18 \\
$25 \%$ & -0.0077 & 0.16 & -1.58 & 0.16 \\
Mean & -0.0004 & 0.38 & -0.08 & 0.38 \\
Median & -0.0015 & 0.28 & -0.4 & 0.28 \\
$75 \%$ & 0.0009 & 0.72 & 0.2 & 0.73 \\
$90 \%$ & 0.007 & 0.45 & 1.13 & 0.64 \\
$95 \%$ & $0.0533^{* * *}$ & 0.00 & $7.74^{* * *}$ & 0.00 \\
\hline
\end{tabular}

Note: Significance at the 1,5 and 10 percent levels are indicated by ${ }^{* *},{ }^{* *}$, and ${ }^{*}$ respectively. 


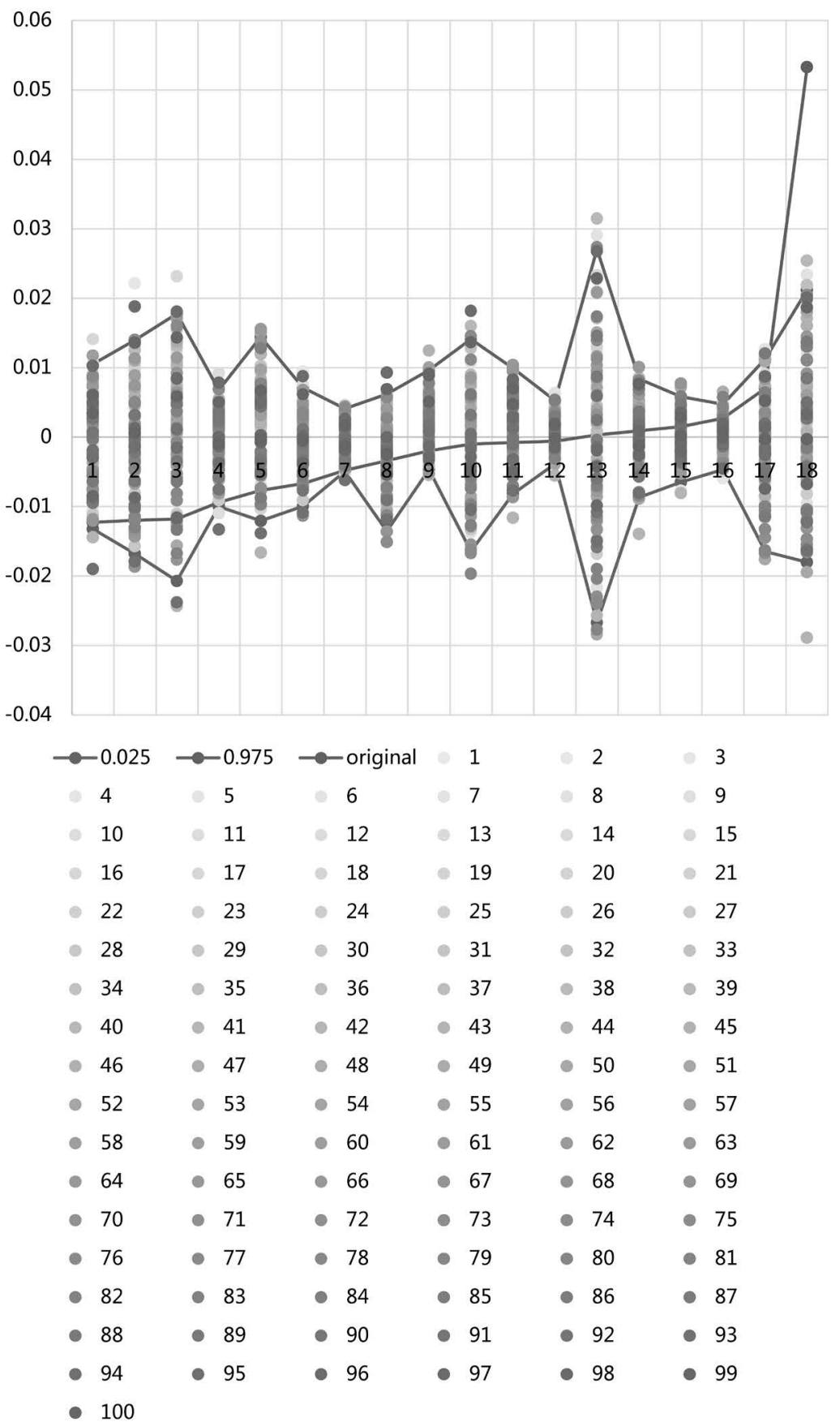

Figure 6. The bootstrap procedure of discount-rate timing.

Table 7. Empirical results of aggregate market return timing.

\begin{tabular}{cccccc}
\hline \multicolumn{5}{c}{ Panel A: Descriptive Statistics } \\
\hline Mean & Minimum & Maximum & S.D. & Skewness & Kurtosis \\
\hline 0.0028609 & -0.0044626 & 0.0564499 & 0.0136895 & 3.591589 & 14.64456 \\
\hline \multicolumn{5}{c}{ Panel B: Tests of Significance } \\
\hline Quantiles & Tim & p-value (Tim) & t-statistic & p-value (t-statistic) \\
\hline $5 \%$ & -0.0045 & 0.7 & -0.58 & 0.81 \\
\hline
\end{tabular}




\section{Continued}

\begin{tabular}{ccccc}
\hline $10 \%$ & -0.0042 & 0.6 & -0.63 & 0.68 \\
$25 \%$ & -0.0021 & 0.52 & -0.42 & 0.55 \\
Mean & 0.0029 & 0.35 & 0.53 & 0.36 \\
Median & -0.0007 & 0.41 & -0.15 & 0.4 \\
$75 \%$ & 0.0016 & 0.63 & 0.28 & 0.58 \\
$90 \%$ & 0.006 & 0.52 & 0.8 & 0.65 \\
$95 \%$ & $0.0564^{* * *}$ & 0.00 & $6.63^{* * *}$ & 0.00 \\
\hline
\end{tabular}

Note: Significance at the 1, 5 and 10 percent levels are indicated by ${ }^{* * *},{ }^{* *}$, and ${ }^{\star}$ respectively.

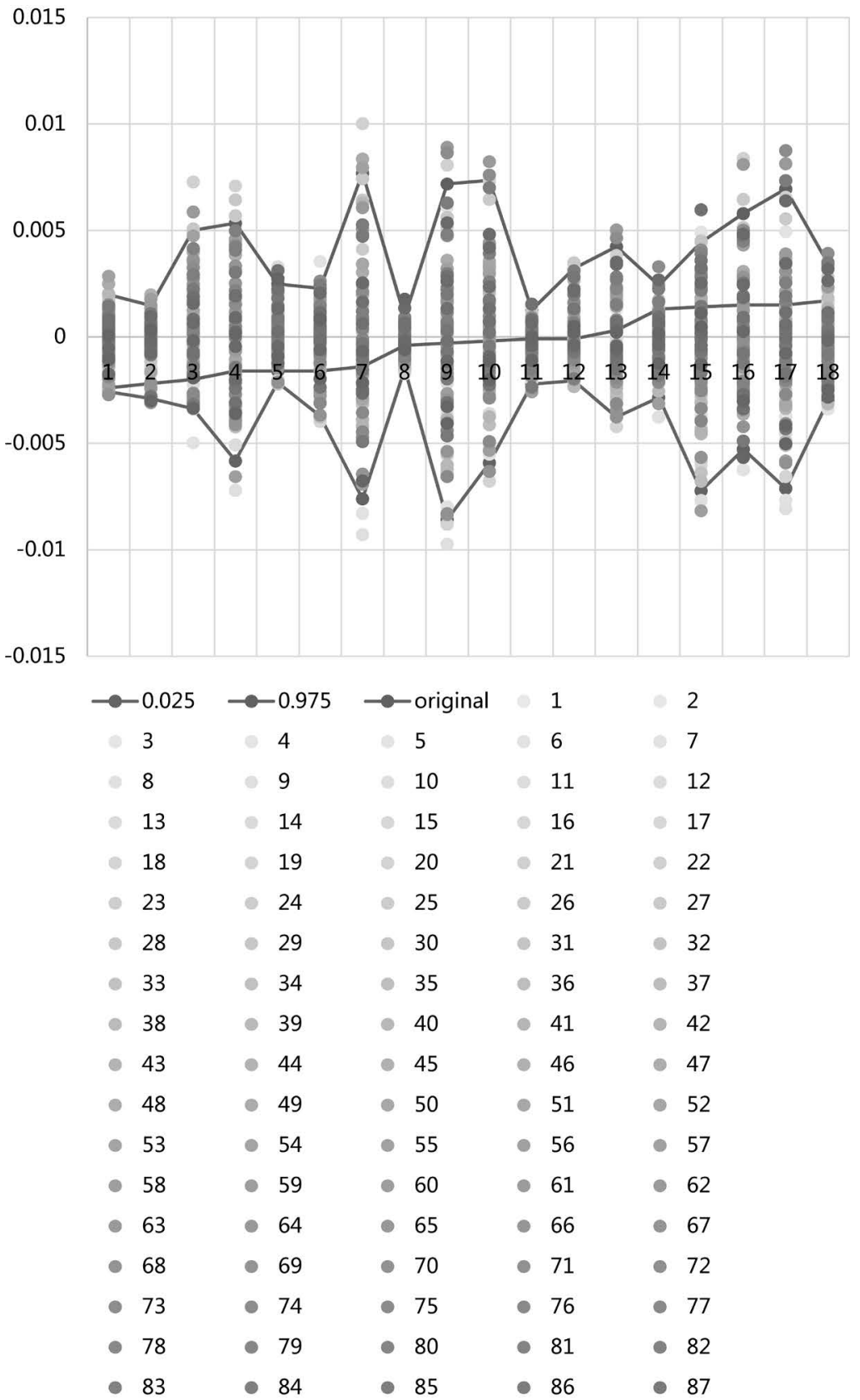

Figure 7. The $95 \%$ confidence interval of bootstrap procedure of total market timing. 
standard deviation and range of total timing measure are also similar to those of discount-rate news timing. What's more, we find that the funds who rank the top in timing the discount-rate news are exactly those who perform best in total market timing. Therefore, we believe that market-timing ability only exists in those fund managers who is good at timing the discount rate.

\subsection{Market Timing Response to Total Market Return Shocks}

To make a comparison, Table 8 reports the results of timing the market returns without decomposition of 18 actively managed equity funds in China during the sample period based on the differential timing measure in Equation (6). To find out the cross-sectional features among these funds, we also sort them into the $5^{\text {th }}, 10^{\text {th }}, 25^{\text {th }}, 75^{\text {th }}, 90^{\text {th }}$ and $95^{\text {th }}$ percentiles according to their market-timing performance.

There are some differences when we treat the market return as one piece in the regression. First is that on average, equity funds make a negative return of $-0.17 \%$ instead of $0.29 \%$ when we divide the market return. The second one is that funds in the $5 \%$ percentile suffer a significant loss of $2.57 \%$, which implies there is only evidence that supports negative market-timing ability. But according to the $95 \%$ confidence interval in Figure 8, none of the 18 funds reveal a significant timing ability respect to the total market return. And the market-timing performance and the corresponding $\mathrm{p}$-values in the two-tail part are much larger in absolute value when decomposing the market return. The possible reason behind this phenomenon is that if the total market return is take as a one-piece object, then there is only one systematic risk, which underestimates the total systematic risks faced by each stock in the fund's portfolio and is quite vague for investors to consider when making investment decisions. However, when we

Table 8. Empirical results of total market return timing.

\begin{tabular}{cccccc}
\hline \multicolumn{5}{c}{ Panel A: Descriptive Statistics } \\
\hline Mean & Minimum & Maximum & S.D. & Skewness & Kurtosis \\
\hline-0.0016884 & -0.0257076 & 0.0017182 & 0.0061489 & -3.559956 & 14.5254 \\
\hline \multicolumn{7}{c}{ Qunel B: Tests of Significance } \\
\hline Tim & p-value (Tim) & t-statistic & p-value (t-statistic) \\
\hline $10 \%$ & $-0.0257^{* * *}$ & 0.00 & $-11.91^{* * *}$ & 0.00 \\
$25 \%$ & -0.0024 & 0.37 & -1.21 & 0.62 \\
Mean & -0.0016 & 0.28 & -1 & 0.39 \\
Median & -0.0017 & 0.13 & -1.1 & 0.18 \\
$75 \%$ & -0.0003 & 0.46 & -0.23 & 0.46 \\
$90 \%$ & 0.0013 & 0.32 & 0.72 & 0.40 \\
$95 \%$ & 0.0015 & 0.47 & 0.73 & 0.64 \\
\hline
\end{tabular}

Note: Significance at the 1,5 and 10 percent levels are indicated by ${ }^{* * *}$,**, and ${ }^{*}$ respectively. 


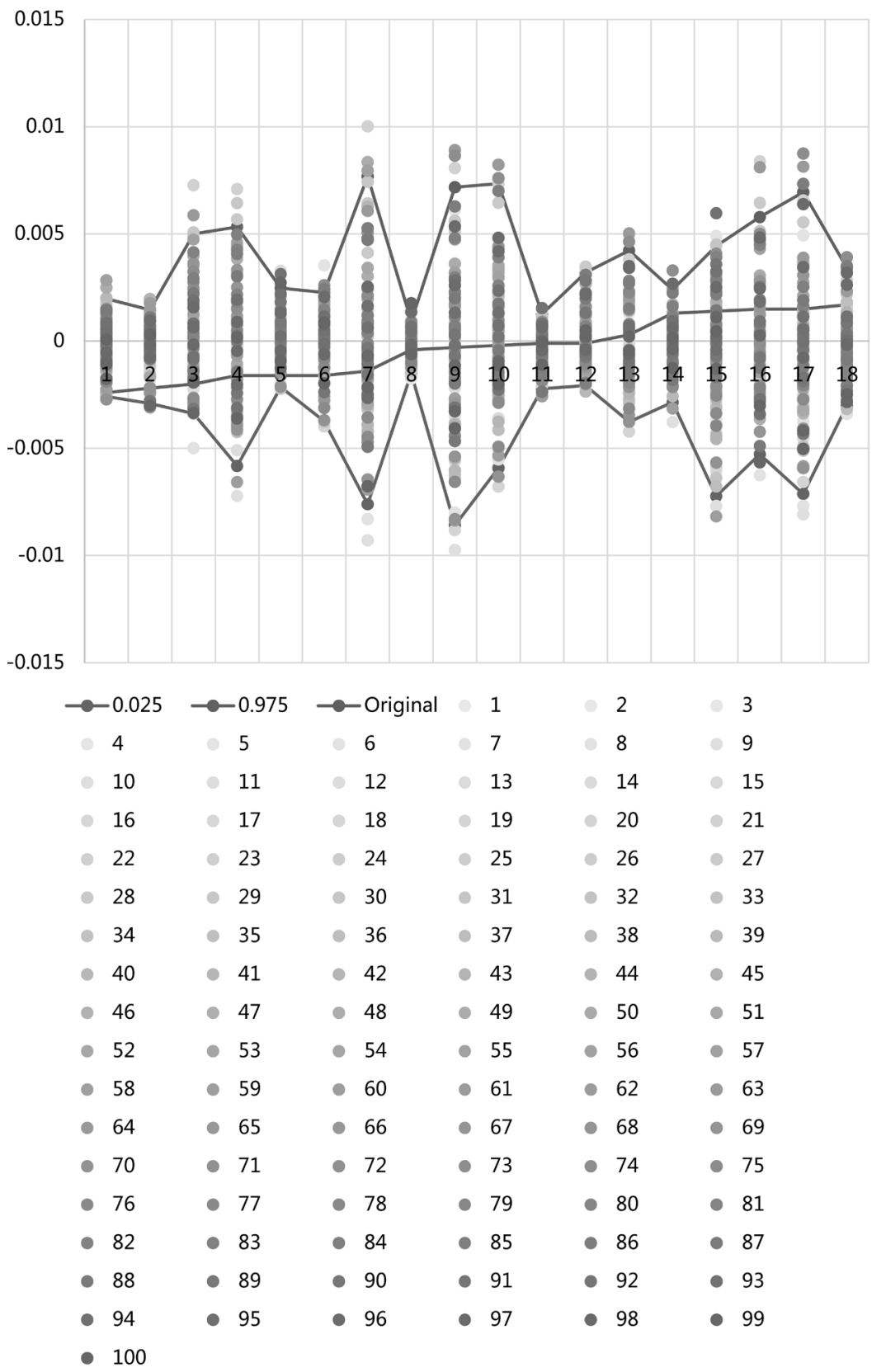

Figure 8 . The $95 \%$ confidence interval of bootstrap procedure of total market return timing.

divide the total market return into two parts, the total systematic risks for each stock are more precisely estimated. Hence, higher systematic risks mean higher uncertainty and fund managers can show a larger or lower market-timing performance when timing the market into 2 parts.

\subsection{Persistence of Market-Timing Ability}

As discussed in the former part, on average, fund managers do not make any significant positive market-timing return based on different systematic factors from 2012 to 2016. In order to determine whether this situation occurs by chance 
or because of no timing ability, the persistence of market-timing skill based on the assumption that this skill really exists is worth checking. If the results reveal that market-timing ability cannot persist for a certain period, then the conclusion that equity fund managers in China are still unable to win the whole market will be illustrated with more certainty.

In Table 9, Panel A, B and $\mathrm{C}$ show that the persistence of market-timing ability does not exist even for 1 year. For example, in Panel A, those funds which make the most return over the past one year when marketing cash-flow news do not continue this trend in the next 6 months. Instead, funds in the third quintile based on the cash-flow market-timing performance outperform others in the next half year. The similar conditions can be found in both the Panel B and Panel C. Besides, the t-statistic of each point, which is reported with parenthesis, is far away from the critical values to reject the null hypothesis that the persistence of market-timing skill does not exist. These findings further illustrate that the equity fund managers in China do not have the market-timing ability.

Table 9. Persistence of market-timing ability.

\begin{tabular}{|c|c|c|c|}
\hline \multirow{2}{*}{ Quintiles } & \multicolumn{3}{|c|}{ Panel A: Cash-flow news } \\
\hline & 1 year & 1.5 year & 2 years \\
\hline \multirow[t]{2}{*}{1 (low) } & -0.0135 & -0.0066 & -0.0092 \\
\hline & $(-0.5567)$ & $(-0.3084)$ & $(-0.4331)$ \\
\hline \multirow[t]{2}{*}{2} & 0.002 & 0.0031 & -0.0091 \\
\hline & $(0.3327)$ & $(0.3004)$ & $(-0.3642)$ \\
\hline \multirow[t]{2}{*}{3} & 0.0064 & -0.0033 & -0.0024 \\
\hline & $(0.2836)$ & $(-0.5096)$ & $(-0.6786)$ \\
\hline \multirow[t]{2}{*}{4} & -0.004 & -0.004 & -0.0064 \\
\hline & $(-0.1922)$ & $(-0.2141)$ & $(-0.3087)$ \\
\hline \multirow[t]{2}{*}{5 (high) } & 0.0003 & -0.0083 & -0.003 \\
\hline & $(0.0094)$ & $(-0.2928)$ & $(-0.5624)$ \\
\hline \multirow[t]{2}{*}{5 - 1 spread } & 0.0138 & -0.0017 & 0.0062 \\
\hline & $(0.4358)$ & $(-0.1077)$ & $(0.3756)$ \\
\hline \multirow{2}{*}{ Quintiles } & \multicolumn{3}{|c|}{ Panel B: Discount-rate news } \\
\hline & 1 year & 1.5 year & 2 years \\
\hline \multirow[t]{2}{*}{1 (low) } & 0.0036 & 0.0097 & 0.0062 \\
\hline & $(0.1416)$ & $(0.3652)$ & $(0.3659)$ \\
\hline \multirow[t]{2}{*}{2} & 0.0006 & 0.0022 & 0.0071 \\
\hline & $(0.0147)$ & $(0.155)$ & $(0.4566)$ \\
\hline \multirow[t]{2}{*}{3} & -0.0115 & 0.0002 & -0.0007 \\
\hline & $(-0.4599)$ & $(0.0184)$ & $(-0.0536)$ \\
\hline 4 & 0.0058 & -0.0129 & 0.0115 \\
\hline
\end{tabular}


Continued

\begin{tabular}{|c|c|c|c|}
\hline & $(0.3162)$ & $(-0.3148)$ & $(0.3003)$ \\
\hline \multirow[t]{2}{*}{5 (high) } & 0.0106 & 0.0094 & -0.0053 \\
\hline & $(0.4375)$ & $(0.4867)$ & $(-0.1319)$ \\
\hline \multirow[t]{2}{*}{5 - 1 spread } & 0.007 & -0.0004 & -0.0115 \\
\hline & $(0.2392)$ & $(-0.0208)$ & $(-0.3523)$ \\
\hline \multirow{2}{*}{ Quintiles } & \multicolumn{3}{|c|}{ Panel C: Total market return } \\
\hline & 1 year & 1.5 year & 2 years \\
\hline \multirow[t]{2}{*}{1 (low) } & -0.0061 & -0.0064 & -0.0076 \\
\hline & $(-0.3993)$ & $(-0.4249)$ & $(-0.4504)$ \\
\hline \multirow[t]{2}{*}{2} & 0.0000 & -0.0008 & -0.0003 \\
\hline & $(-0.0086)$ & $(-0.1035)$ & $(-0.0388)$ \\
\hline \multirow[t]{2}{*}{3} & -0.0002 & -0.0019 & -0.0017 \\
\hline & $(-0.0311)$ & $(-0.2248)$ & $(-0.1949)$ \\
\hline \multirow[t]{2}{*}{4} & -0.0019 & -0.001 & -0.0009 \\
\hline & $(-0.2095)$ & $(-0.1419)$ & $(-0.0999)$ \\
\hline \multirow[t]{2}{*}{5 (high) } & -0.0004 & 0.0004 & -0.0008 \\
\hline & $(-0.0358)$ & $(0.0427)$ & $(-0.0786)$ \\
\hline \multirow[t]{2}{*}{5 - 1 spread } & 0.0057 & 0.0068 & 0.0068 \\
\hline & $(0.5062)$ & $(0.5301)$ & $(0.5223)$ \\
\hline
\end{tabular}

\section{Conclusion}

This paper investigates the market-timing ability of actively managed equity funds in China by dividing the market return into two parts: the cash-flow news and discount-rate news. By using the differential timing measure respect to a systematic factor (cash-flow news, discount-rate news or the total market return), we find that on average, the 18 equity funds add a value of about $0.58 \%$ per year to the fund when timing the stock market. However, the total market-timing ability performance based on the decomposition mentioned above is not statistically significant except in the $95 \%$ percentile, which is quite similar to the situation when timing the discount-rate news. Hence, we think fund managers who are adept at timing the discount-rate news can bring a positive return when timing the total market. In addition, the continuity of market-timing ability cannot last for even 1 year. Using the decomposition method advocated by Lan and Wermers (2017), we are unable to distinguish funds that have the market-timing ability in China.

\section{Conflicts of Interest}

The authors declare no conflicts of interest regarding the publication of this paper. 


\section{References}

[1] Treynor, J. and Mazuy, K. (1966) Can Mutual Funds Outguess the Market? Harvard Business Review, 44, 131-136.

[2] Eugene, F. (1972) Components of Investment Performance. Journal of Finance, 27, 551-567. https://doi.org/10.1111/j.1540-6261.1972.tb00984.x

[3] Henriksson, R.D. and Merton, R.C. (1981) On Market Timing and Investment Performance II: Statistical Procedures for Evaluating Forecasting Skills. Journal of Business, 54, 513-534. https://doi.org/10.1086/296144

[4] Eugene, F. and Kenneth, F. (1993) Common Risk Factors in the Returns on Stocks and Bonds. Journal of Financial Economics, 33, 3-56.

https://doi.org/10.1016/0304-405X(93)90023-5

[5] Lan, C.H. and Wermers, R. (2017) Cashflow Timing vs Discount-Rate Timing: A Decomposition of Mutual Fund Market-Timing Skills. Proceedings of the 2017 American Finance Association Annual Meetings, Chicago, 6-8 January 2017, 1-58.

[6] Ferson, W.E. and Schadt, R.W. (1996) Measuring Fund Strategy and Performance in Changing Economic Conditions. Journal of Finance, 51, 425-461. https://doi.org/10.1111/j.1540-6261.1996.tb02690.x

[7] Danie, K., Grinblatt, M., Titman, S. and Wermers, R. (1997) Measuring Mutual Fund Performance with Characteristic-Based Benchmarks. Journal of Finance, 52, 1035-1058. https://doi.org/10.1111/j.1540-6261.1997.tb02724.x

[8] Elton, E.J., Gruber, M.J. and Blake, C.R. (2012) An Examination of Mutual Fund Timing Ability Using Monthly Holdings Data. Review of Finance, 16, 619-645. https://doi.org/10.1093/rof/rfr007

[9] Kosowski, R., Timmermann, A., White, H. and Wermers, R. (2006) Can Mutual Fund “Stars" Really Pick Stocks? New Evidence from a Bootstrap Analysis. Journal of Finance, 61, 2551-2595. https://doi.org/10.1111/j.1540-6261.2006.01015.x

[10] Jiang, G.J., Yao, T. and Yu, T. (2007) Do Mutual Funds Time the Market? Evidence from Portfolio Holdings. Journal of Financial Economics, 86, 200-226.

https://doi.org/10.1016/j.jfineco.2006.09.006 